\title{
Feasibility Study on Wastewater Treatment Using Chemically Enhanced Primary Treatment
}

\author{
Mona A. Abdel-Fatah 1,*iD, Ghada A. Al Bazedi ${ }^{1}$, Salwa I. Hawash ${ }^{1}$, Ashraf Amin ${ }^{1}$ \\ 1 Chemical Engineering \& Pilot Plant Department, Engineering Division, National Research Center, El-Bohouth \\ Street, P.O. Box 12622, Dokki, Giza, Egypt; \\ * Correspondence: monamamin7@yahoo.com (M.A.A.F.);
}

Scopus Author ID 57189660075

Received: 5.04.2021; Revised: 1.08.2021; Accepted: 5.08.2021; Published: 12.09.2021

\begin{abstract}
A techno-economic analysis was performed to investigate wastewater treatment feasibility using chemically enhanced primary treatment (CEPT) compared to conventional primary treatment (PT). An experimental study was conducted to investigate the performance of CEPT at optimum conditions, and experimental results were used to feed the techno-economical study with required input data. The wastewater treatment was focused on reducing $\mathrm{BOD}_{5}, \mathrm{COD}$, and TSS. The comparison between CEPT and PT was concerned with removal efficiency and process economics. CEPT process has shown better efficiency compared to PT process. The experimental work indicated that ferric chloride is the optimum coagulant agent since it is highly efficient and available at a low cost. The optimum coagulant experimental results showed that the turbidity removal efficiency was $82 \%$, COD removal $84 \%$, BOD removal $68.1 \%$, and SS removal $85 \%$. The techno-economic study was performed to investigate the feasibility of CEPT. The techno-economic evaluation indicated that CEPT is a costeffective and technically viable process for wastewater treatment. The techno-economic evaluation indicated that CEPT is a cost-effective and technically viable process for wastewater treatment as the operating cost can be reduced by $66 \%$ compared to PT.
\end{abstract}

Keywords: chemical treatment; coagulant; chemically enhanced primary treatment (CEPT); primary treatment; techno-economic evaluation; wastewater.

(C) 2021 by the authors. This article is an open-access article distributed under the terms and conditions of the Creative Commons Attribution (CC BY) license (https://creativecommons.org/licenses/by/4.0/).

\section{Introduction}

Chemically enhanced primary treatment "CEPT" can be defined as particulate and colloids removal using suitable coagulants. CEPT reduces the footprint of the primary settling unit by employing high surface overflow rates. CEPT is a low-cost, effective wastewater treatment and emerging technology for the removal of pollutants and pathogens. CEPT shows a considerable reduction in the wastewater organic loading, leading to a considerable reduction in space and cost of subsequent biological units [1]. To upgrade conventional primary treatment "PT" facility to CEPT, the addition of a chemical coagulant and optionally a flocculent are needed [2].

Adding chemical coagulants and/or polyelectrolyte within PT units will efficiently remove phosphorus, suspended solids, and associated biochemical oxygen demand (BOD5). Efficient removal of organic loading will lead to smaller basins design and allow the treatment unit to process greater overflow rates [3]. CEPT can be applied in two essential ways: (pre- 
pond CEPT) using a modified primary settling tank or employing a second settling tank to add chemicals to wastewater flowing to a stabilization pond [4].

CEPT is used in several wastewater treatment plants to reduce suspended solids and organic loads in the primary clarifier outlet $[3,4]$. CEPT integration improves the effectiveness of existing wastewater treatment plants and increases the plant capacity and removal percentages. CEPT is implemented for a new treatment plant to increase the plant capacity and/or reduce the plant size by almost 50\% [4]. CEPT is a simple and effective way to increase the removal efficiency of Total suspended solids "TSS" from 40-50\% to 60-70\% [5].

In CEPT, chemicals are added to facilitate the faster settlement of suspended solids in wastewater [6]. By adding coagulants, suspended particles coagulate or flocculate together and settle faster. Coagulant addition enhances the treatment process efficiency and improves the removal of solids, organic matter, and nutrients from wastewater. In CEPT, chemicals used in potable water treatment are employed to remove residual metals in the supernatant, e.g., aluminum sulfate and ferric chloride [7]. Aluminum sulfate (alum) is the most common coagulant due to its low cost and availability in different physical forms [8,9]. To ensure the insolubility of aluminum sulfate, alum is used in a $\mathrm{pH}$ range of 4.5 to 8 . Ferric chloride is insoluble in a $\mathrm{pH}$ range of 2 to 12 . Flocks formed using ferric salts settled rapidly due to higher density than those formed using alum [8].

Different coagulants are used and investigated widely in literature, like mustard and bean seeds. The coagulation-flocculation process treated synthetic municipal wastewater to examine the effectiveness of mustard powder and mustard cake coagulants prepared from naturally available mustard [9]. Natural coagulants extracted from common bean seeds were used efficiently in the primary treatment of distillery wastewater in the bio-ethanol production from sugar beet juice as an environmentally friendly coagulant [10].

However, three conventional coagulants are commercially used to remove dissolved and chemical species and turbidity from water: alum $\left(\mathrm{AlCl}_{3}\right)$, ferric chloride $\left(\mathrm{FeCl}_{3}\right)$, and poly aluminum chloride (PAC) [11]. Adding $300 \mathrm{ppm}$ of alum and $1 \mathrm{ppm}$ of polymer reduced color by $95 \%$, turbidity by $75 \%$, Chemical oxygen demand "COD" by $76 \%$, and phosphorus by $90 \%$ [12]. CEPT can be used as an efficient de-colorization method of industrial waste effluents, further improving treatment process economics $[12,13]$. Both alum and ferric chloride exhibit excellent settling characteristics, with the majority of the flock, settle quickly in the first 5 min [14]. Improving the efficiency and performance of the primary treatment process will increase treatment unit capacity and minimize overall energy consumption [15]. The CEPT process provides great potential for improving wastewater treatment performance and process economics [16].

Based on the published experimental results [17], the optimum conditions of CEPT using different coagulants are further studied in this article. The removal efficiency of CEPT is investigated under optimum experimental conditions on lab and industrial scales. The experimental study deliberated different treatment cases, including the combined effect of alum, ferric chloride, or lime with a cationic polymer. The feasibility of wastewater treatment using CEPT is examined. Based on the experimental results, an economic study is performed to evaluate the economics of CEPT process application in wastewater treatment, considering the most economical coagulants as indicated by the experimental results.

The main objective of this study is a decision-making tool for selecting the proper treatment CEPT option. Moreover, this study compares the cost, volume, and energy consumption of different treatment techniques, including CEPT and PT. 


\section{Materials and Methods}

The experimental study is established based on our previous work that provides an ecofriendly approach for CEPT of wastewater [17]. The experimental setup is described in detail in a published work [17]. A brief description of the experimental study parameters and conditions is given below in Table 1. According to [17], the most promising coagulants are tested at optimum operating conditions. Different coagulants were used in the study, including alum, ferric chloride, and polymers. The experimental study was focused on investigating the effect of coagulant (ferric chloride, alum, lime, and coagulant aids), coagulant dose, stirring time, and $\mathrm{pH}$ solution on the treatment efficiency, focusing on reduction in $\mathrm{BOD}_{5}, \mathrm{COD}$, and TSS. Experimental conditions used in the lab and the industrial-scale CEPT units are summarized in Table 1. The effect of operating parameters on wastewater treatment efficiency was investigated by varying coagulant types (ferric chloride, alum, lime, and coagulant aids), coagulant dose, stirring time, and $\mathrm{pH}$.

Table 1. Operating conditions on lab-scale (LS) and full scale (FS).

\begin{tabular}{l|l|l} 
Item Tested & $(\mathbf{L S})$-Values Tested & $($ FS)-Values Tested \\
\hline Optimum $\mathrm{pH}$ for alum & $4-9$ & 6 \\
\hline Optimum pH for $\mathrm{FeCl}_{3}$ & $3-8$ & 4 \\
\hline Optimum $\mathrm{pH}$ for lime & $5.5-11.5$ & 8.5 \\
\hline Doses of alum & $10-180 \mathrm{mg} / \mathrm{L}$ & 80 \\
\hline Doses of $\mathrm{FeCl}_{3}$ & $10-120 \mathrm{mg} / \mathrm{L}$ & 40 \\
\hline Doses of lime & $200-1200 \mathrm{mg} / \mathrm{L}$ & 200 \\
\hline Doses of coagulant aid with alum & $0.1-0.6 \mathrm{mg} / \mathrm{L}$ & 0.4 \\
\hline Doses of coagulant aid with $\mathrm{FeCl}_{3}$ & $0.1-0.6 \mathrm{mg} / \mathrm{L}$ & 0.3 \\
\hline Optimal mixing speed & $50-80 \mathrm{RPM}$ & 50 for alum, 70 for $\mathrm{FeCl}_{3}$ and lime \\
\hline Optimal mixing time & $6-20 \mathrm{~min}$ & 12 for alum, 12 or 20 for $\mathrm{FeCl}_{3}, 16$ for lime \\
\hline Optimal settling time & $10-40 \mathrm{~min}$ & 20 for alum \& $\mathrm{FeCl}_{3}$ and 30 for lime
\end{tabular}

\section{Results and Discussion}

\subsection{Results of treatability processes.}

3.1.1. Determination of optimum coagulant doses.

The experimental results indicated that CEPT had improved the capacity and removal efficiency of wastewater treatment. The removal percentages achieved with CEPT using different coagulation mixtures compared to PT are shown in Table 2. Removal percentages observed with different coagulants are shown in Table 2. The measured removal percentages considered the following pollutants: TSS, COD, and $\mathrm{BOD}_{5}$.

Table 2. Average removal percentage of pollutants for different treatment methods.

\begin{tabular}{|c|c|c|c|c|c|c|c|c|}
\hline \multirow[b]{2}{*}{$\begin{array}{l}\text { Pollutant } \\
\text { removal }\end{array}$} & \multicolumn{8}{|c|}{$\%$ Removal with treatment method } \\
\hline & Initial & PT & alum & $\begin{array}{c}\text { alum + } \\
\text { polymer }\end{array}$ & $\mathrm{FeCl}_{3}$ & $\begin{array}{l}\mathrm{FeCl}_{3}+ \\
\text { polymer }\end{array}$ & lime & $\begin{array}{c}\text { lime }+ \\
\text { Polymer }\end{array}$ \\
\hline TSS & $271 \mathrm{mg} / \mathrm{l}$ & 44.2 & 89.3 & 88.4 & 92.3 & 92.7 & 80.1 & 76.7 \\
\hline COD & $314 \mathrm{mg} / \mathrm{l}$ & 51.7 & 88.3 & 83.1 & 86.9 & 82.0 & 75.9 & 81.1 \\
\hline $\mathrm{BOD}_{5}$ & $484 \mathrm{mg} / \mathrm{l}$ & 45.7 & 68.9 & 72.7 & 77.4 & 83.2 & 59.4 & 70 \\
\hline
\end{tabular}

The highest removal percentage is observed at a settling time of 30 minutes and $50 \mathrm{rpm}$. Using the optimum dose, the best removal percentages of TSS, COD, and $\mathrm{BOD}_{5}$ are shown in Table 2. As shown in Table 2, an optimum alum dosage was $50 \mathrm{mg} / \mathrm{l}$, since, by any increase in the coagulant dose, the observed efficiency does not significantly increase [18]. A higher $\mathrm{FeCl}_{3}$ dose yields a yellow color in the supernatant layer due to the existence of iron ions. The 
optimum dosage of lime was $400 \mathrm{mg} / \mathrm{l}$. Optimum values for $\mathrm{pH}$ were $6,4,11.2$ for alum, $\mathrm{FeCl}_{3}$, and lime, respectively.

\subsubsection{Effect of adding polymer to coagulants.}

As shown in Figures 1-3, adding Magnofloc155 as a coagulant aid has no significant effect on the removal percentage using $\mathrm{FeCl}_{3}$. Magnofloc155 addition has shown a slight increase in removal percentage (2\%) with alum. Magnofloc155 addition has shown a slight decrease in removal percentage with lime.

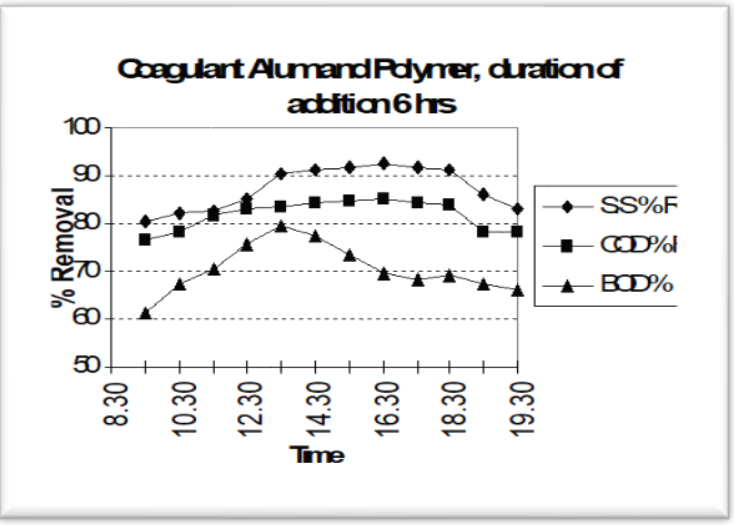

Figure 1. Removal efficiencies vs. time using alum and polymer

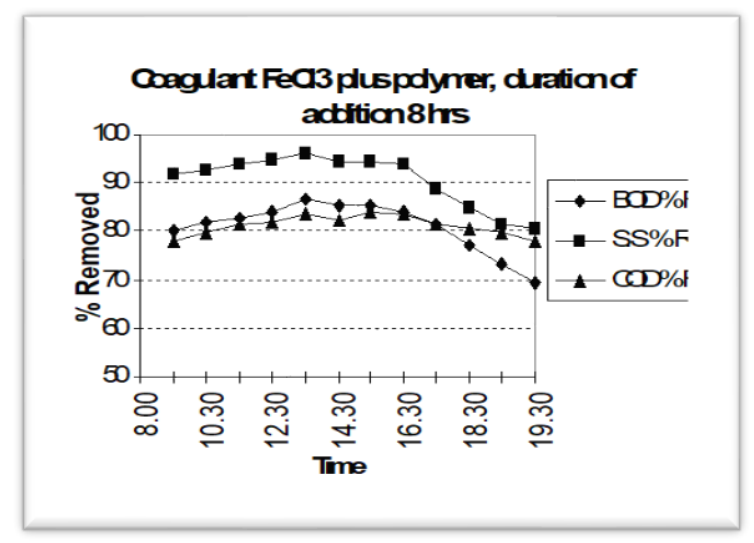

Figure 2. Removal efficiency vs. time using $\mathrm{FeCl}_{3}$ and polymer

The effect of adding polyacrylamide as a coagulant aid $(0.1 \mathrm{mg} / \mathrm{l})$ was investigated using the optimum dose of each coagulant. The effect of polyacrylamide addition on the removal percentage is illustrated in Figure 4. With an alum dose of $70 \mathrm{mg} / \mathrm{l}$ at $\mathrm{pH} 7$, the removal percentage was $92.8,85.3$, and $79.6 \%$ for $\mathrm{SS}, \mathrm{COD}$, and $\mathrm{BOD}_{5}$, respectively. Using $40 \mathrm{mg} / \mathrm{l}$ of $\mathrm{FeCl}_{3}$, the removal percentage was $96.3,84.2$, and $86.7 \%$ for SS, COD, and BOD , respectively. By adding polyacrylamide to a $600 \mathrm{mg} / \mathrm{l}$ of lime solution, the removal percentage was 82.8 , 77.9 , and $69.5 \%$ for $\mathrm{SS}, \mathrm{COD}$, and $\mathrm{BOD}_{5}$, respectively.

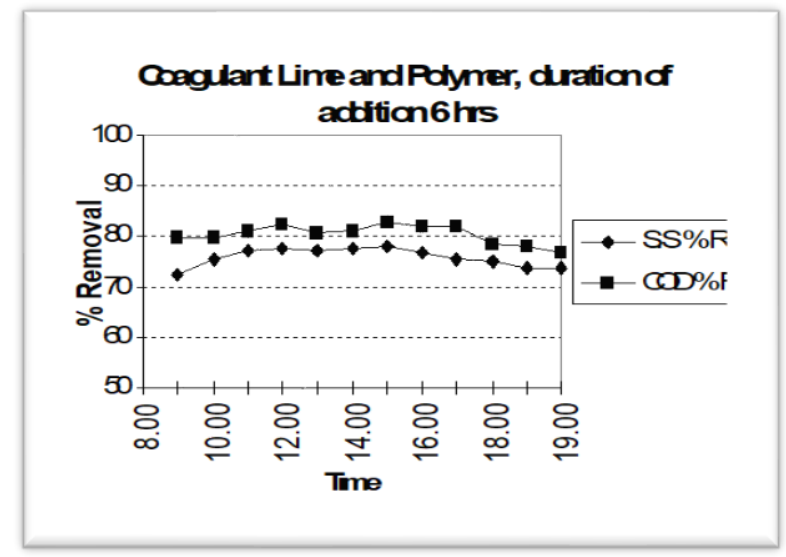

Figure 3. Effect of lime plus polymer on \% removal with settling time

The effect of adding polyacrylamide is shown in Figure 4. Figure 4 shows a comparison of the removal percentages using different coagulants with/without polyacrylamide. Adding polyacrylamide has shown a considerable positive effect on the removal percentage achieved with alum. Polyacrylamide addition has almost no effect on removal percentage with $\mathrm{FeCl}_{3}$ and a negative effect in the case of lime. 


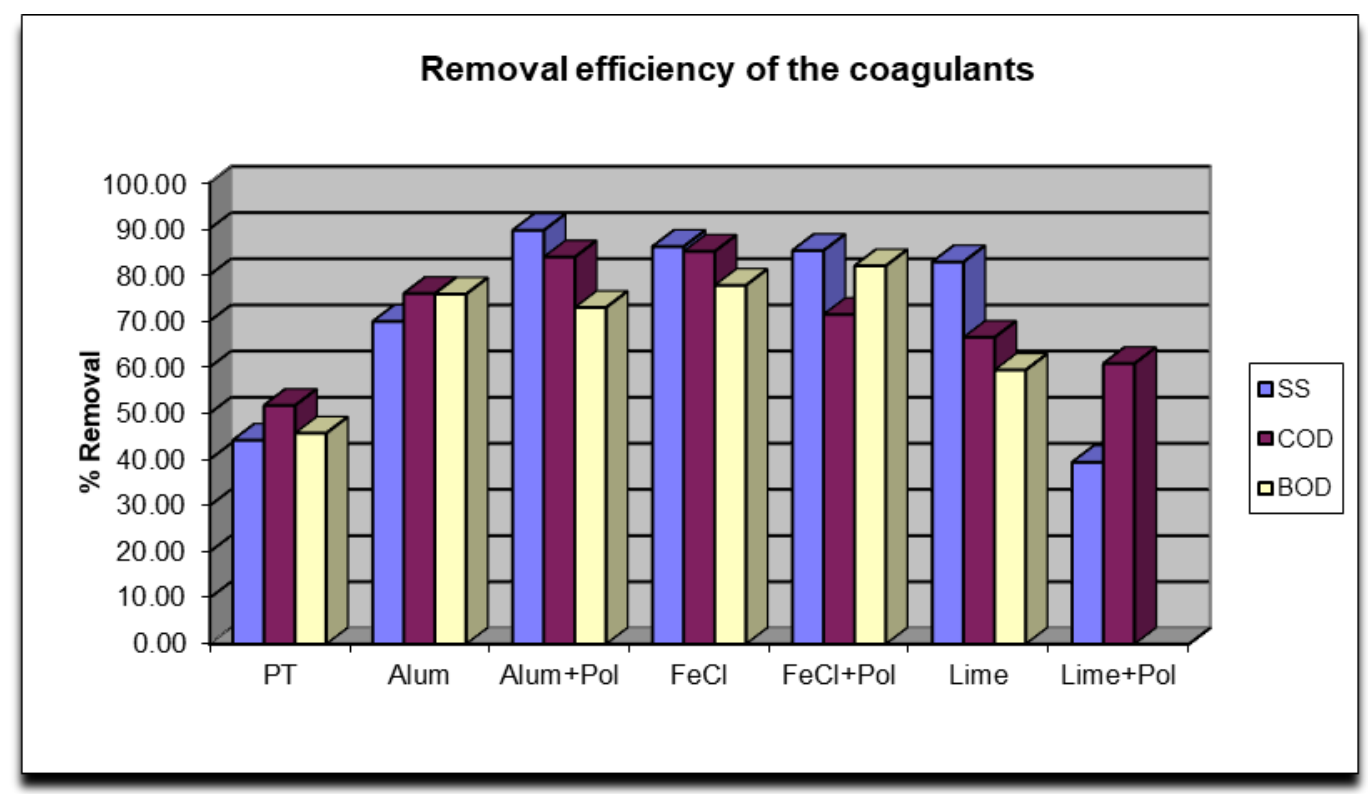

Figure 4. Effect of adding polyacrylamide to coagulants in removing TSS, COD, and $\mathrm{BOD}_{5}$.

\subsubsection{Effect of CEPT on the removal of heavy metals.}

The removal percentage of heavy metals achieved by CEPT is investigated using samples with different concentrations of $\mathrm{Ni}$ and using alum as a coagulant. A $40 \%$ and $17 \%$ removal percentage were achieved with wastewater samples containing 0.5 and $0.6 \mathrm{mg} / \mathrm{l}$ of $\mathrm{Ni}$, respectively.

\subsubsection{Evaluation of CEPT efficiency.}

An industrial unit was developed to study CEPT efficiency on an industrial scale. Samples of wastewater effluent from the grit removal chamber and the primary sedimentation effluent were fed to the developed industrial unit to compare the efficiency of CEPT with the conventional wastewater treatment method. The coagulants were added at the optimum dose of each coagulant according to the results depicted from the lab-scale study. The results observed on an industrial scale are discussed below: The turbidity of treated water: Turbidity observed with alum or $\mathrm{FeCl}_{3}$ was $82 \%$ and $81 \%$, respectively, which was observed at optimum operating conditions. The addition of lime does not affect turbidity; COD removal: increased to $94.7 \%$ using alum, $90.7 \%$ using $\mathrm{FeCl}_{3}$, and $84 \%$ using lime; SS removal: $94.6 \%$ using alum, 95.5\% using $\mathrm{FeCl}_{3}$, and $85 \%$ using lime; $\mathrm{BOD}_{5}$ removal: $84.3 \%$ using alum, $79.1 \%$ using $\mathrm{FeCl}_{3}$, and $68.1 \%$ using lime.

By adding Alum, $\mathrm{FeCl}_{3}$, or lime as a coagulant at their optimum operating condition, the removal of COD, $\mathrm{BOD}_{5}$, Turbidity, and TSS was achieved using CEPT after $30 \mathrm{~min}$, was comparable to the maximum removal in primary settling tanks after a settling time of $240 \mathrm{~min}$.

\subsection{Preliminary techno-economic evaluation.}

The techno-economic evaluation was conducted by considering several economics studies of wastewater processes. CEPT and PT were compared based on the Internal Rate of Return and Net Present Value. According to the preliminary techno-economic evaluation, CEPT is more cost-efficient than PT, and ferric chloride is the most efficient coagulant from an economic point of view. 
CEPT can achieve the same removal efficiency in $1 / 8$ the time required for PT. The required settling time in the settlement tanks is only $30 \mathrm{~min}$. for CEPT and $240 \mathrm{~min}$ for PT. Or, the CEPT plant can treat eight times the capacity of the PT within the same equipment volume. In CEPT, additional investment is needed for chemicals storage, dosage tanks, and dosage pumps.

The operating cost is affected largely by the consumption of chemicals within CEPT. In this study, different CEPT coagulating agents are considered. The cost-efficiency of CEPT process using different coagulants is compared to the PT considering the following factors: The cost of coagulant; The optimal coagulant dose required to achieve the desired treatment level; Cost per $\mathrm{kg}$ pollutant removed is calculated by dividing the total costs by the number of pollutants removed.

The techno-economic evaluation is conducted for alum, ferric chloride, and lime milk, with/without polymer addition.

\subsubsection{Overall cost comparison between CEPT and PT.}

The comparison between PT and CEPT was performed, considering the capital, operating, and maintenance costs. The capital cost required for CEPT and PT is shown in Table 3, considering the extra costs required for CEPT operation. The actual operating costs of PT plant are estimated, assuming an operating volume of $10,000 \mathrm{~m}^{3}$. The cost for such a plant is approximately 60 million Egyptian Pounds. For CEPT plant, only an eighth of this volume is needed, and therefore one plant would only cost 7,750,000 Egyptian Pounds, including 250,000 Egyptian Pounds for extra equipment to account for the required capital investment related to the use of chemicals.

Table 3. Capital costs with and without enhanced treatment.

\begin{tabular}{l|c|c} 
Capital Costs Egyptian Pounds & PT & CEPT \\
\hline Investment cost for the plain plant & $60,000,000$ & $7,500,000$ \\
\hline Extra costs for CEPT method & - & 250,000 \\
\hline Total capital costs & $60,000,000$ & $7,750,000$
\end{tabular}

The operating costs of PT and CEPT plants are shown in Table 4. Extra costs for chemicals/ coagulant supplies are the only remarkable difference between PT and CEPT. Other operating costs are expected to be approximately the same for the two alternatives. Coagulant supplies are expected to account for $75 \%$ of CEPT plant operating costs. The economic utilization of these chemicals is very important. The optimum dose and optimum treatment time are studied in detail, as shown in the experimental results. This depends on the choice of efficient coagulant for the CEPT.

Table 4. Operating costs of PT and CEPT.

\begin{tabular}{l|c|c} 
Categories & PT (Egyptian Pounds) & CEPT (Egyptian Pounds) \\
\hline Labor & 192,975 & 192,975 \\
\hline Electricity & 204,552 & 204,552 \\
\hline Materials \& Supplies & 5,515 & 5,515 \\
\hline Lubricants & 7,970 & 7,970 \\
\hline Fuel & 21,600 & 21,600 \\
\hline Maintenance Supplies & 20,520 & 20,520 \\
\hline Lab Supplies & 5,184 & 5,184 \\
\hline Coagulant Supplies & 0 & depends on alternative used
\end{tabular}

Different quantities are needed from each coagulant to achieve optimal removal. On the lab scale, these optimal quantities were established during the experimental study. The 
experimental results show the necessary quantities, the price per coagulant and the total costs for the different coagulants are listed in Table 5.

Table 5. Prices, quantities, and total costs for the different coagulants.

\begin{tabular}{l|c|c|c|c|c} 
Chemical Costs & Tons use/day & Total ton/year & Price LE/ton & Total cost & Total with use of polymer \\
\hline Aluminum Sulfate & 8.4 & 3,066 & 325 & 996,450 & $1,640,250$ \\
\hline Ferric Chloride & 6 & 2,190 & 850 & $1,861,500$ & $1,905,300$ \\
\hline Lime milk & 36 & 13,140 & 80 & $1,051,200$ & $1,095,000$ \\
\hline Polymer & 0.006 & 2.19 & 20,000 & 43,800 & --
\end{tabular}

Due to the remarkable difference in price and the quantity required for each coagulant, the total cost for the different coagulants may vary from 1-6.2 million Egyptian Pounds since the price may vary considerably depending on the quantity. In addition, the total cost is affected by the efficiency of different coagulants to remove pollutants. In Figure 5, the removal percentage of TSS, COD, and $\mathrm{BOD}_{5}$ is shown. Comparing different coagulants, ferric chloride and aluminum sulfate are the most efficient in pollutant removal, as shown in Figure 5. The addition of polymer can be avoided since it does not have a considerable effect. Avoiding polymer costs will improve overall process economics, as shown in Table 5.

The total annual PT and CEPT costs are summarized in Table 6 below. The overall capital costs are annualized to compare the two alternatives based on a certain expected life service. Assuming a life span of the plant of 10 years, the annuity payments are distributed over 10 years with an interest rate of $8 \%$. Then, the annuity payments will be considered as annual costs.

Table 6. Total annual costs for primary treatment and CEPT with different coagulants. (with extra fixed costs annualized based upon a lifetime of 10 years)

\begin{tabular}{l|c|c|c}
$\begin{array}{l}\text { Cost category } \\
\text { Treatment method }\end{array}$ & $\begin{array}{c}\text { Annual operating } \\
\text { costs (in LE) }\end{array}$ & $\begin{array}{c}\text { Annualized capital } \\
\text { costs (in LE) }\end{array}$ & $\begin{array}{c}\text { Total annual costs } \\
\text { (in LE) }\end{array}$ \\
\hline Primary Treatment & 458,316 & $6,111,133$ & $6,569,449$ \\
\hline Aluminum Sulfate & $1,454,766$ & 788,336 & $2,243,102$ \\
\hline Aluminum Sulfate + Polymer & $1,498,566$ & 788,336 & $2,997,132$ \\
\hline Ferric Chloride & $2,319,816$ & 788,336 & $3,108,152$ \\
\hline Ferric Chloride + Polymer & $2,363,616$ & 788,336 & $3,151,952$ \\
\hline Lime milk & $1,509,516$ & 788,336 & $2,297,852$ \\
\hline Lime milk + Polymer & $1,553,316$ & 788,336 & $2,341,652$
\end{tabular}

Table 6 shows the total annual costs for primary treatment and CEPT with different coagulants. By adding the capital investment, the total yearly cost of CEPT is less than half of the PT total yearly costs. The total annual cost of CEPT using any coagulants understudy is lower than the total annual cost of PT, as shown in Table 6. The operational costs are higher in the case of CEPT, which is attributed to the associated cost of coagulant.

CEPT is a more economical option compared to PT; it is important to study the economics of using different coagulants. An effective way to compare the operating cost associated with each coagulant is to calculate the costs $/ \mathrm{kg}$ of pollutants removed. With the high removal percentages of CEPT, the total yearly removed amount of pollutants can be calculated using the average influent ratio for each coagulant. The influent ratio was multiplied by the total daily flow and the number of days in a year to calculate the total yearly influent in $\mathrm{kg}$. Consequently, the different amounts of $\mathrm{kg}$ removed were found, as shown in Table 7. The CEPT showed more efficient removal compared to PT. 
Table 7. Total amount of pollutants removed with the different treatment methods.

\begin{tabular}{l|c|c|c}
$\begin{array}{l}\text { Pollutant } \\
\text { Treatment method }\end{array}$ & $\begin{array}{c}\text { Total yearly BOD5 } \\
\text { removed }(\mathbf{k g})\end{array}$ & $\begin{array}{c}\text { Total yearly COD } \\
\text { removed (kg) }\end{array}$ & $\begin{array}{c}\text { Total yearly SS } \\
\text { removed (kg) }\end{array}$ \\
\hline Primary Treatment & $5,614,656$ & $9,540,220$ & $4,494,787$ \\
\hline Aluminum Sulfate & $9,317,875$ & $12,827,499$ & $7,163,799$ \\
\hline Aluminum Sulfate + Polymer & $8,959,493$ & $14,162,210$ & $9,189,689$ \\
\hline Ferric Chloride & $9,550,932$ & $14,368,891$ & $8,828,524$ \\
\hline Ferro Chloride + Polymer & $10,069,829$ & $12,059,404$ & $8,740,290$ \\
\hline Lime milk & $7,294,753$ & $11,222,743$ & $8,487,282$ \\
\hline Lime milk + Polymer & NA & $10,263,803$ & $4,038,924$
\end{tabular}

Finally, the last step in comparing the economic feasibility of CEPT and the most economical coagulant is to divide the total amount of pollutants removed by the total cost of different coagulants. Table 8 shows a detailed comparison of the cost of each treatment method per Kg of pollutants removed. The treatment cost was estimated for each coagulant assuming the optimum dose as observed during the experimental study for the CEPT process. The cost estimation has shown that CEPT is more economical than regular PT, which can be attributed to two reasons: the total costs for a wastewater treatment plant based upon CEPT are only an eighth of the costs for a plant based on PT; the removal efficiency for the CEPT method is higher than the efficiency of the ordinary PT method.

Table 8. Cost per $\mathrm{Kg}$ of pollutants removed.

\begin{tabular}{l|c|c|c}
$\begin{array}{l}\text { Cost (in LE) per category of } \\
\text { Treatment method }\end{array}$ & $\begin{array}{c}\text { Kg SS } \\
\text { removed }\end{array}$ & Kg COD removed & Kg BOD5 removed \\
\hline Primary Treatment (PT) & 1.45 & 0.75 & 1.17 \\
\hline Aluminum Sulfate & 1.30 & 0.20 & 0.24 \\
\hline Aluminum Sulfate + Polymer & 0.30 & 0.20 & 0.30 \\
\hline $\mathrm{FeCl}_{3}$ & 0.35 & 0.22 & 0.33 \\
\hline $\mathrm{FeCl}_{3}+$ Polymer & 0.36 & 0.26 & 0.31 \\
\hline Lime milk & 0.27 & 0.20 & 0.32 \\
\hline Lime milk + Polymer & 0.58 & 0.23 & $\mathrm{NA}$ \\
\hline Average for all CEPT methods & 0.54 & 0.33 & 0.46
\end{tabular}

The cost-efficiency of different removal methods is shown in Figure 5. When comparing the cost per $\mathrm{kg}$ removed for different coagulants, $\mathrm{FeCl}_{3}$ and lime milk are the lowest cost per $\mathrm{Kg}$ of the pollutant removed. Considering the total amount of pollutants removed in Table 2, $\mathrm{FeCl}_{3}$ is more efficient than lime milk. So, $\mathrm{FeCl}_{3}$ is the optimum coagulant choice; it is preferred over lime milk due to the higher removal percentage of pollutants.

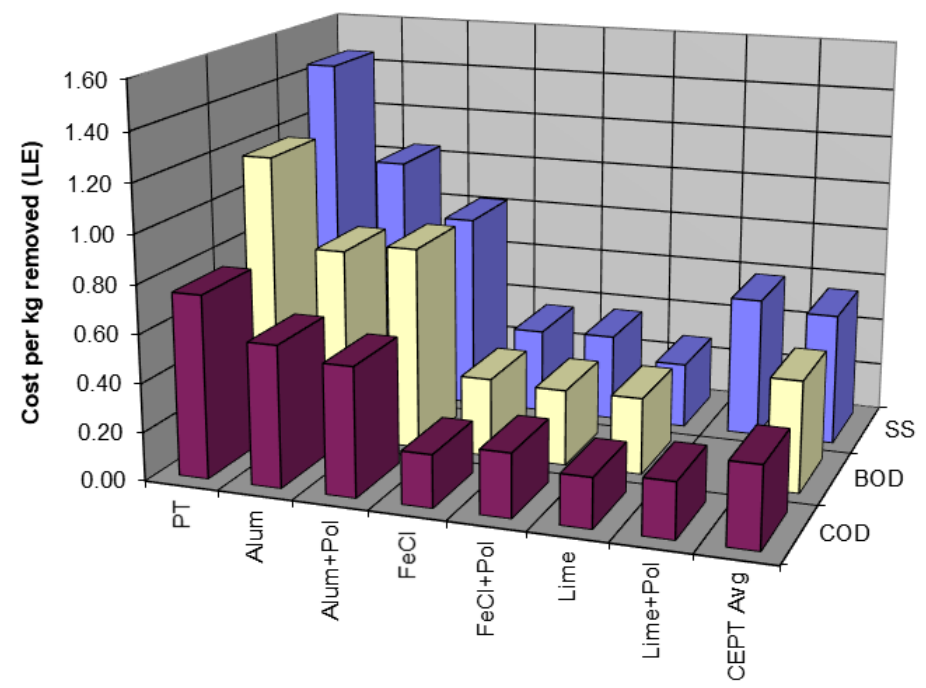

Figure 5. Cost efficiency of the different methods of wastewater treatment. 


\section{Conclusions}

A techno-economic study for using CEPT in wastewater treatment was conducted to investigate the feasibility of applying the process. CEPT and PT were investigated experimentally on lab and industrial scales using different coagulants. The CEPT process is an efficient method for removing $\mathrm{BOD}_{5}, \mathrm{COD}$, turbidity, and TSS. 90\% removal of TSS and turbidity were achieved, and around $80 \%$ of COD removal was achieved. CEPT reduced the settling time to $30 \mathrm{~min}$, compared to $240 \mathrm{~min}$ in PT. The performance of different coagulants in CEPT process was further investigated using optimum operating conditions on lab and industrial scale to provide the required information for a techno-economical study.

Experimental results of the optimum coagulant showed that the turbidity removal efficiency was $82 \%$, COD removal $84 \%$, $\mathrm{BOD}_{5}$ removal $68.1 \%$, and SS removal $85 \%$. The techno-economic study was performed to investigate the feasibility of CEPT. The CEPT system is distinguished with lower yearly annualized costs. CEPT shows a pollutant removal cost per Kg lower than PT. The techno-economic evaluation indicated that CEPT is a costeffective and technically viable process for wastewater treatment. The techno-economic evaluation indicated that CEPT is a cost-effective and technically viable process for wastewater treatment as the operating cost can be reduced by $66 \%$ compared to PT.

\section{Funding}

This research received no external funding.

\section{Acknowledgments}

This research has no acknowledgment.

\section{Conflicts of Interest}

The authors declare no conflict of interest.

\section{References}

1. Xu, G.R.; Yan, Z.C.; Wang, Y.C.; Wang, N. Recycle of Alum recovered from water treatment sludge in chemically enhanced primary treatment. Journal of Hazardous Materials 2009, 161, 663-669, https://doi.org/10.1016/j.jhazmat.2008.04.008.

2. Haydar, S.; Aziz, J.A. Characterization and treatability studies of tannery wastewater using chemically enhanced primary treatment (CEPT) - A case study of Saddiq Leather Works. Journal of Hazardous Materials 2009, 163, 1076-1083, https://doi.org/10.1016/j.jhazmat.2008.07.074.

3. Yu, I.W. Bench-scale study of chemically enhanced primary treatment in Brazil. M.Sc. Thesis, Massachusetts Institute of Technology, USA, 2006.

4. Taboada-Santos, A.; Rivadulla, E.; Paredes, L.; Carballa, M.; Romalde, J.; Lema, J.M. Comprehensive comparison of chemically enhanced primary treatment and high-rate activated sludge in novel wastewater treatment plant configurations. Water Research 2020, 169, https://doi.org/10.1016/j.watres.2019.115258.

5. Rusten, B.; Rathnaweera, S.S.; Rismyhr, E.; Sahu, A.K.; Ntiako, J. Rotating belt sieves for primary treatment, chemically enhanced primary treatment and secondary solids separation. Water science and technology : a journal of the International Association on Water Pollution Research 2017, 75, 2598-2606, https://doi.org/10.2166/wst.2017.145.

6. Wang, H.; Li, F.; Keller, A.A.; Xu, R. Chemically enhanced primary treatment (CEPT) for removal of carbon and nutrients from municipal wastewater treatment plants: a case study of Shanghai. Water Science and Technology 2009, 60, 1803-1809, https://doi.org/10.2166/wst.2009.547.

7. Al Bazedi, G.A.; Abdel-Fatah, M.A. Correlation between operating parameters and removal efficiency for chemically enhanced primary treatment system of wastewater. Bulletin of the National Research Centre 2020, 44, https://doi.org/10.1186/s42269-020-00368-y. 
8. Johnson, P.D.; Girinathannair, P.; Ohlinger, K.N.; Ritchie, S.; Teuber, L.; Kirby, J. Enhanced Removal of Heavy Metals in Primary Treatment Using Coagulation and Flocculation. Water Environment Research 2008, 80, 472-479, https://doi.org/10.2175/106143007x221490.

9. Villaseñor-Basulto, D.L.; Astudillo-Sánchez, P.D.; del Real-Olvera, J.; Bandala, E.R. Wastewater treatment using Moringa oleifera Lam seeds: A review. Journal of Water Process Engineering 2018, 23, 151-164, https://doi.org/10.1016/j.jwpe.2018.03.017.

10. Prodanović, J.M.; Šćiban, M.B.; Antov, M.G.; Kukić, D.V.; Vasić, V.M. Treatment of sugar beet extraction juice stillage by natural coagulants extracted from common bean. Acta periodica technologica 2015, 46, 7789, https://doi.org/10.2298/apt1546077p.

11. Yin, C.-Y. Emerging usage of plant-based coagulants for water and wastewater treatment. Process Biochemistry 2010, 45, 1437-1444, https://doi.org/10.1016/j.procbio.2010.05.030.

12. Asif, N.; Ali, S.S.; Bhatti, Z.; Zafar, R. Chemically Enhanced Primary Wastewater Treatment (CEPT) in conjunction with $\mathrm{H} 2 \mathrm{O} 2 / \mathrm{UV}$ technology in controlled atmosphere. Research Journal of Environmental and Earth Sciences 2013, 5, 153-159, https://doi.org/10.19026/rjees.5.5652.

13. Ebeling, J.M.; Ogden, S.R.; Sibrell, P.L.; Rishel, K.L. Application of Chemical Coagulation Aids for the Removal of Suspended Solids (TSS) and Phosphorus from the Microscreen Effluent Discharge of an Intensive Recirculating Aquaculture System. North American Journal of Aquaculture 2004, 66, 198-207, https://doi.org/10.1577/a03-056.1.

14. Gupta, M. Microsieving as a Primar ving as a Primary Treatment for Biological Nitr eatment for Biological Nitrogen Removal from Municipal Wastewater. The University of Western Ontario. 2018.

15. Abdel-Fatah, M.A.; Shaarawy, H.H.; Hawash, S.I. Integrated treatment of municipal wastewater using advanced electro-membrane filtration system. SN Applied Sciences 2019, 1, https://doi.org/10.1007/s42452019-1178-9.

16. Mcnamara, B.; Eng, G. Economic and Environmental Cost Assessment of Wastewater Treatment Systems A Life Cycle Perspective. School of Mechanical and Manufacturing Engineering Dublin University. 2018.

17. Fatah, M.M.A.A.; Al Bazedi, G.A. Chemically enhanced primary. European Journal of Engineering and Technology Research 2019, 4, 115-123, https://doi.org/10.24018/ejers.2019.4.4.1252. 